\title{
Partisipasi Masyarakat Dalam Musrembang Di Desa Pajalele Kecamatan Tellu Limpoe Kabupaten Sidenreng Rappang
}

\author{
Nilam sari \\ Prodi Administrasi Publik. Fakultas Ilmu Sosial Dan Politik \\ Universitas Muhammadiyah Sidenreng Rappang \\ Email : Nilamsari1221@gmail.com
}

\begin{abstract}
ABSTRAK
Tujuan penelitian untuk mengetahui partisipasi masyarakat desa dalam penyusuan rencana pembangunan desa Pajalele dapat menjadi salah satu tolak ukur sejauh mana desa tersebut mengembangkan nilai-nilai tata kelola pemerintahan desa yang baik dalam roda pemerintahanya. Partisipasi masyarakat dalam Musyawarah Perencanaan Pembangunan (Musrenbang) di Desa Pajalele Kecamatan Tellu Limpoe Kabupaten Sidenreng Rappang. Jenis pengumpulan data ini adalah metode deskriptif dengan pendekatan kualitatif. Populasi penelitian ini adalah seluruh masyarakat di Desa Pajalele Kecamatan Tellu Limpoe Kabupaten Sidenreng Rappang dan sampel yaitu masyarakat yang dianggap banyak mengetahui terhadap masalah yang dihadapi dan diharapkan agar responden yang dipilih mewakili populasi yaitu 80 orang. Penelitihan ini menunjukkan bahwa Pastisipasi Musyawarah Dalam Perencanaan Pembangunan (Musrenbang) di Desa Pajalele Kecamatan Tellu Limpoe Kabupaten Sidenreng Rappang berada pada kategori baik, partisipasi masyarakat dalam musyawarah perencanaan pembangunan berada pada kategori sangat baik, dan Faktor-faktor yang mempengaruhi peranan pemerintah desa dan partisipasi masyarakat dalam Musyawarah Perencanaan Pembangunan berada pada kategori baik
\end{abstract}

\section{Kata Kunci : Partisipasi Masyarakat;Musrenbang}




\begin{abstract}
The purpose of the study to determine the participation of the village community in the preparation of the Pajalele village development plan can be one of the benchmarks for the extent to which the village develops the values of good village governance in the wheels of government. Community participation in the Development Planning Deliberation (Musrenbang) in Pajalele Village, Tellu Limpoe District, Sidenreng Rappang Regency. This type of data collection is a descriptive method with a qualitative approach. The population of this research is the entire community in Pajalele Village, Tellu Limpoe District, Sidenreng Rappang Regency and the sample is people who are considered to know a lot about the problems they are facing and it is hoped that the selected respondents represent the population of 80 people. This research shows that Participation of Deliberations in Development Planning (Musrenbang) in Pajalele Village, Tellu Limpoe District, Sidenreng Rappang Regency is in the good category, community participation in development planning deliberation is in the very good category, and the factors that influence the role of village government and community participation in the Development Planning Deliberation is in the good category.
\end{abstract}

\title{
Keywords: Community Participation; Musrenbang
}

\section{PENDAHULUAN}

Perencanaan pembangunan adalah proses pengembangan kapasitas masyarakat dalam jangka panjang sehingga memerlukan perencanaan yang tepat dan akurat. Perencanaan ini harus mampu mencakup kapan, di mana dan bagaimana pembangunan harus dilakukan agar mampu mendorong pertumbuhan ekonomi dan sosial secara berkesinambungan(Mustanir \& Abadi, 2017). 
Pemerintah daerah punya kewenangan yang lebih dalam perencanaan, pengelolaan anggaran dan pelaksanaan pembangunan. Artinya terjadi perubahan paradigma sistem pemerintahan, baik ditingkat pusat, provinsi, dan daerah. Perubahan tersebut menuntut paradigma baru dalam perencanaan pembangunan daerah. Perencanaan pembangunan daerah yang bersifat desentralisasi membuka era baru bagi pemerintahan daerah yang ada(Mustanir \& Abadi, 2017).

Sistem Perencanaan Pembangunan Nasional di Indonesia mengenal duapendekataan top down dan bottom up untuk menjamin keseimbangan antara prioritas nasional dengan aspirasi prioritas lokal, walaupun kenyataanya sebagian besar daerah belum mengakomodasi aspirasi lokal dikarenakan sebagian besar proposal program yang diajukan berdasarkan aspirasi lokal telah tersingkir dalam rapat kordinasi yang menempatkan proposal yang diajukan oleh tingkat pemerintahan yang lebih tinggi tanpa memperhatikan proposal yang diajukan oleh tingkat pemerintahan yang dibawahnya(Mustanir \& Abadi, 2017).

Good governance adalah suatu bentuk manajemen pembangunan, yang juga disebut disebut sebagai administrasi pembangunan. Pada dasarnya, penerapan tata pemerintahan yang baik merupakan pelayan publik yang lebih baik kepada masyarakat, maka dari itu good governance ini sangat penting di terapkan di Desa Damai Kecamatan Watang Sidenreng Kabupaten Sidenreng Rappang. Manajemen pembangunan atau administrasi pembangunan menempatkan peran pemerintah sentral. Maka pemerintah menjadi (agen perubahan), dari suatu masyarakat (developing) dalam negara berkembang, khususnya pada wilayah daerah(Zhilviana Sulaeman, Ahmad Mustanir, 2019).

Partispasi masyarakat merupakan suatu proses yangdapat mendukung masyarakat untuk mulai "sadar" akan situasi dan masalah yang dihadapinya serta berupaya mencari jalan keluar yangdapat dipakai untuk mengatasi masalah mereka (memiliki kesadaran kritis). Sumardi (2010:46), mengemukakan bahwa partisipasi adlah peran serta seseorang atau kelompok masyarakat dalam proses pembangunan baik dalam bentuk pernyataan maupun dalam bentuk kegiatan dengan memberi masukan pikiran, tenaga, waktu, keahlian, modal, dan atau materi, serta ikut memanfaatkan dan menikmati hasil-hasil pembangunan(Zhilviana Sulaeman, Ahmad Mustanir, 2019). 


\section{TINJAUAN PUSTAKA}

\section{- Konsep Partisipasi Masyarakat}

Perencanaan pembangunan suatu kumpulan kebijaksanaan dan program pembangunan untuk merangsang masyarakat dan swasta untuk menggunakan sumber daya yang tersedia secara lebih produktif. Arthur W. Lewis (2005). Perencanaan pembangunan adalah cara atau teknik untuk mencapai tujuan pembangunan secara tepat, terarah dan efisien sesuai dengan kondisi daerah yang bersangkutan. Sjafrizal (2014 : 24). Musrenbang adalah forum-forum multi-pihakterbuka yang secara bersama mengidentifikasi dan menentukan prioritas kebijakan pembangunan masyarakat. Musyawarah perencanaan pembangunan (musrenbang) kelurahan adalah forum musyawarah tahunan para pemangku kepentingan (stakeholders) kelurahan untuk menyepakati rencana kerja kelurahan tahun anggaran berikutnya. Tim Kerja Buku Panduan Penyelenggaraan Musrenbang dalam Ahmad Mustanir (2016)(Mustanir \& Rusdi, 2018)

Partisipasi anggota masyarakat merupakan keterlibatan anggota masyarakat dalam pembangunan, meliputi kegiatan dalam perencanaan dan pelaksanaan (implementasi) program/proyek pembangunan yang dikerjakan di dalam masyarakat 2 . Sedangkan Partisipasi masyarakat dalam pembangunan diartikan ikut sertanya masyarakat dalam pembangunan, ikut dalam kegiatan pembangunan dan ikut serta pemanfaatan dan menikmati hasil pembangunan34. Berdasarkan hal tersebut maka partisipasi masyarakat adalah suatu aktivitas yang mengikutsertakan perasaan dan emosional seseorang dalam proses pembuatan keputusan dan melaksanakan tanggung jawab dalam suatu organisasi atau kelompok dalam mencapai tujuan bersama yang telah ditetapkan. Partisipasi masyarakat adalah pemberdayaan masyarakat, peran sertanya dalam

kegiatan penyusunan perencanaan implementasi program/proyek pembangunan, dan merupakan aktualisasi dan kesediaan dan kemauan masyarakat untuk berkorban dan berkontribusi terhadap implementasi Program Pembangunan5(Mustanir \& Rusdi, 2018).

(Mustanir et al., 2018)Menurut (A. Mustanir, Yasin, et al. 2018) terdapat beberapa pengertian dasar mengenai partisipasi masyarakat, di antaranya adalah sebagai berikut. 
1) Partisipasi masyarakat adalah peran serta masyarakat dalam berbagai kegiatan individu, kelompok atau badan hukum yang timbul atas kehendak dan keinginan sendiri ditengah masyarakat, untuk berminat dan bergerak di penyelenggaraan penataan ruang (Barisan, Ramadhan, and Mustanir 2017) (A. Mustanir and Rusdi 2019).

2) Partisispasi masyarakat adalah keterlibatan masyarakat sesuai dengan hak dan kewajibannya sebagai obyek dan subjek pembangunan, keterlibatan dalam tahap pembangunan dimulai sejak tahap perencanaan sampai pengawasan berikut segala hak dan tanggun jawabnya (A. Mustanir 2016) (A. Mustanir, Justira, et al. 2018).

Menurut Conyers dalam (A. Mustanir and Lubis 2017), mengemukakan bahwa ada tiga alasan utama mengapa partisipasi masyarakat sangat penting yaitu :

1. Partisipasi masyarakat merupakan suatu alat guna memperoleh informasi mengenai kondisi, kebutuhan dan sikap masyarakat setempat;

2. Masyarakat akan lebih percaya proyek atau program pembangunan jika merasa dilibatkan dalam proses persiapan dan perencanannya;

\section{- Musyawarah Rencana Pembangunan (Musrembang Desa)}

Perencanaan pembangunan merupakan suatu tahapan awal dalam proses pembangunan.Sebagai tahapan awal, perencanaan pembangunan akan menjadi bahan/pedoman/acuan dasar bagi pelaksanaan kegiatan pembangunan (Riyadi \& Bratakusumah, 2004) (Mustanir and Rusdi. Muhammad 2019). Perencanaan pembangunan juga berlaku bagi negara-negara yang sedang berkembang, karena ada bebrapa faktor, yaitu karena kegagalan mekanisme pasar, ketidakpastian masa datang, untuk mengarahkan kegiatan pembangunan. Indonesia merupakan salah satu negara berkembang yang tak luput dengan mekanisme parencanaan pembangunan dengan adanya SPPN (system perencanaan pembangunan nasional) Undang-Undang Nomor 24 Tahun 2004. Yang mana perencanaan pembangunan bukan hanya dilakukan pada tingkat pusat namun pada tingkat daerah juga. Dalam konteks pelaksanaan pembangunan daerah, sesuai denganperan pemerintah daerah dalam era otonomi luas, perencanaan pembangunan daerah diperlukan kerana pelaksanaan pembangunan didesentralisasikan dari pemerintah pusat kepada pemerintah daerah(Mustanir et al., 2020). 
Istilah kebijakan atau sebagian orang mengistilahkan kebijaksanaan seringkali disamakan pengertiannya dengan istilah policy. Hal tersebut barangkali dikarenakan sampai saat ini belum diketahui terjemahan yang tepat istilah policy ke dalam Bahasa Indonesia. Kebijakan dalam definisi yang mashur menurut Dye adalah whatever government choose to do or not to do. Maknanya Dye hendak menyatakan bahwa apapun kegiatan pemerintah baik yang eksplisit maupun implisit merupakan kebijakan. Dye dalam Indiahono menguraikan beberapa pengertian tentang kebijakan yang telah dikemukakan oleh para ilmuwan tersebut, kiranya dapatlah ditarik kesimpulan bahwa pada hakekatnya studi tentang policy (kebijakan) mencakup pertanyaan: what, why, who, where, dan how2. Semua pertanyaan itu menyangkut tentang masalah yang dihadapi lembaga-lembaga yang mengambil keputusan yang menyangkut; isi, cara atau prosedur yang ditentukan, strategi, waktu keputusan itu diambil dan dilaksanakan. Implementas(Mustanir \& Darmiah, 2016).

Implementasi berkenaan dengan berbagai kegiatan yang diarahkan pada realisasi program3. Implementasi kebijakan merupakan tahapan yang sangat penting dalam keseluruhan struktur kebijakan. Tahap ini menentukan apakah kebijakan yang ditempuh oleh pemerintah benar-benar aplikabel di lapangan dan berhasil menghasilkan output dan outcomes seperti direncanakan. Untuk dapat mewujudkan output dan outcomes yang ditetapkan, maka kebijakan publik perlu untuk diimplementasian tanpa diimplementasikan maka kebijakan tersebut hanya akan menjadi catatan-catatan elit sebagaimana dipertegas oleh Udoji yang mengatakan bahwa pelaksanaan kebijakan adalah sesuatu yang penting bahkan mungkin jauh lebih penting daripada pembuatan kebijakan(Mustanir \& Darmiah, 2016).

\section{METODE PENELITIAN}

Penelitian ini menggunakan metode deskriptif kualitatif. (Moleong, 2010 : 3) Teknik pengumpulan data yang dilakukan adalah: melalui Penelitian Lapangan dengan cara observasi dan wawancara (Data Primer), Studi kepustakaan/library research (membaca buku, majalah, surat kabar, dokumen-dokumen, dan media informasi lain dan Penelusuran data online yakni menggunakan fasilitas internet (Data Sekunder). Untuk mendapatkan hasil yang obyektif dalam penelitian ini, maka data yang didapatkan dilapangan akan diolah dan dianalisa secara kualitatif, 
yaitu dengan menggambarkan dan menjelaskan hasil-hasil penelitian dari sejumlah data-data yang telah diperoleh.

\section{PEMBAHASAN}

Budaya politik partisipan. Tipe budaya politik yang ketiga, budaya partisipan adalah suatu bentuk kultur dimana anggota-anggota masyarakat cenderung di orientasikan secara eksplisitterhadap sistem sebagai keseluruhan dan terhadap struktur dan proses politik serta administratif ; dengan kata lain, terhadap aspek input dan output dari sistem politik itu. Anggotaanggota pemerintahan yang partisipatif dapat secara menyenangkan atau sebaliknya di arahkan kepada berbagai obyek politik yang serba ragam. Mereka cenderung di arahkan kepada peranan pribadi sebagai aktivis masyarakat, sekalipun perasaan dan evaluasi meraka terhadap peranan yang demikian bisa saja bersifat menerima ataupun menolaknya (Almond, 20:1990)(Mustanir \& Jaya, 2016).

Good governance pada pencapaiannya wajib didukung sang public service menjadi orientasi pada penyelenggaraan pelayanan. Pelayanan publik sebagai bagian krusial pada pencapaian tujuan pemerintahan yang baik. Bahkan, pelayanan publik membutuhkan pelayanan yang sama, tidak memiliki evaluasi yang negatif terhadap pelayanan yang diberikan. Menurut Safroni (2012), bahwa karakteristik-karakteristik pelayanan birokrasi yang berkualitas merupakan pelayanan yang bersifat anti birokrasi, distribusi pelayanan, dan desentralisasi dan berorientasi dalam klien, penekannya menggunakan cara: Pemerintah membangun suasana kompetitif dalam memberikan pelayanan; Pemerintah berorientasi pada kebutuhan pasar, bukan birokrasi; Pemerintahan desentralisasi dan lebih proaktif. Tetapi demikian, kesamaan yang terdapat merupakan bahwa apabila pelayanan pada suatu forum negara diberikan menggunakan cara yang kurang baik, maka sebagai stempel bagi forum negara tadi(Yenni Jamal, Ahmad Mustanir, 2020).

Perencanaan pembangunan sendiri merupakan sebuah proses pengembangan kapasitas masyarakat dalam jangka panjang sehingga memerlukan perencanaan yang tepat dan akurat. Perencanaan ini berarti harus mampu mencakup kapan, di mana dan bagaimana pembangunan harus dilakukan agar mampu merangsang pertumbuhan ekonomi dan sosial masyarakat secara 
berkesinambungan.Perencanaan pembangunan daerah yang bersifat desentralisasi membuka era baru bagi pemerintahan daerah. Dimana dalam Sistem Perencanaan Pembangunan Nasional Indonesia saat ini menggunakan dua pendekataan top down dan bottom up tujuannya untuk menjamin keseimbangan antara prioritas nasional dengan aspirasi prioritas lokal, walaupun pada kenyataanya sebagian besar daerah belum mengakomodasi aspirasi lokal dikarenakan sebagian besar program yang diajukan berdasarkan aspirasi lokal telah tersingkir dalam rapat kordinasi yang menempatkan proposal yang diajukan oleh tingkat pemerintahan yang lebih tinggi tanpa memperhatikan proposal yang diajukan oleh tingkat pemerintahan yang lebih rendah("Transect Pada Perencanaan Pembangunan Partisipatif," 2018).

partisipasi masyarakat disini merupakan keikutsertaan dalam melakukan kegiatan pengidentifikasian problem dan potensi-potensi yang ada didalam masyarakatnya. Proses dalam pengambilan keputusan dalam pemilihan penanganan masalah, upaya dalam mengatasi masalah serta keterlibatan mereka dalam mengevaluasi perubahan yang ada. Dalam masyarakat harus tumbuh kesadaran akan eksistentinya, karena masyarakat mempunyai peran dalam keberhasilan perencanaan pembangunan bersama pemerintah. Ditahap awal proses pembangunan, perencanaan pembangunan merupakan pedoman penting bagi terlaksananya kegiatan pembangunan itu sendiri. Sehingga perencanaan pembangunan hendaknya dapat bersifat aplikatif dan dapat diimplementasikan. Selain itu perencanaan yang dibuat hendaklah tidak terlalu mengatur dan mampu menyentuh segala aspek kehidupan dimasyarakat, serta mampu mengikuti tuntunan perubahan disekitarnya secara nyata. Dalam memperoleh output dari hasil perencanaan pembangunan yang terbaik, maka keterlibatan masyarakat di dalamnya sangat dibutuhkan, karena masyarakat adalah salah satu unsur yang terpenting dalam pembangunan. Terlibatnya peran serta masyarakat proses perencanaan menandakan bahwa pihak pemerintah sudah memberikan sebuah kepercayaan pada partisipasi masyarakat untuk ikut merasa bertanggung jawab dalam program yang telah di rencanakan(Adam Latif 1, Irwan2, 2019)

Masyarakat yang telah mengetahui dan memahami jika di kelurahan mereka terdapat lembaga yang dapat melaksanakan kegiatan pemberdayaan masyarakat seperti LPM, PKK, atau BKM sangat menyayangkan lembaga tersebut karena tidak menjalankan fungsi sebagaimana mestinya dan menganggap bahwa lembaga tersebut dibentuk hanya sebagai pelengkap di kelurahan mereka(Mustanir et al., 2019). 


\section{DAFTAR PUSTAKA}

Adam Latif 1, Irwan2, A. M. (2019). Analisis Kepemimpinan Terhadap Optimalisasi Masyarakat Pada Perencanaan Pembangunan Di Enrekang. Analisis Kebijakan Dan Pelayanan Publik, 5(2), 1-20. https://doi.org/10.20956/xxxxxx

Mustanir, A., \& Abadi, P. (2017). Partisipasi Masyarakat Dalam Musyawarah Rencana Pembangunan Di Kelurahan Kanyuara Kecamatan Watang Sidenreng Kabupaten Sidenreng Rappang. Jurnal Politik Profetik, 5(2), 247-261. http://journal.uinalauddin.ac.id/index.php/jpp/article/viewFile/4347/3986\%0Ahttp://journal.uinalauddin.ac.id/index.php/jpp/issue/view/636

Mustanir, A., \& Darmiah, D. (2016). Implementasi Kebijakan Dana Desa Dan Partisipasi Masyarakat Dalam Pembangunan Di Desa Teteaji Kecamatan Tellu Limpoe Kabupaten Sidenreng Rappang. Jurnal Politik Profetik, 4(2), 225-238. http://journal.uinalauddin.ac.id/index.php/jpp/article/view/2749\%0Ahttp://journal.uinalauddin.ac.id/index.php/jpp/issue/view/457

Mustanir, A., Fitriani, S., Adri, K., Nurnawati, A. A., \& Goso, G. (2020). Sinergitas Peran Pemerintah Desa dan Partisipasi Masyarakat Terhadap Perencanaan Pembangunan di Kabupaten Sidenreng Rappang (The Synergy of Village Government's Role and Community Participation in the Process of Development Planning in Sidenreng Rappang D. Journal of Government Science (GovSci), 2020, 1(2): 84-108, 2020(2), 84-108.

Mustanir, A., \& Jaya, I. (2016). Pengaruh Kepemimpinan Dan Budaya Politik Terhadap Perilaku Pemilih Towani Tolotang Di Kecamatan Maritengngae Kabupaten Sidenreng Rappang. Jurnal Politik Profetik, 4(1), 84-97. http://journal.uinalauddin.ac.id/index.php/jpp/article/view/2741\#\%0Ahttp://journal.uinalauddin.ac.id/index.php/jpp/issue/view/430

Mustanir, A., Kamarudding, S., Akhwan, A., Madaling, \& Mutmainna. (2018). Peranan Aparatur Pemerintahan Desa dan Partisipasi Masyarakat Dalam Musyawarah Perencanaan Pembangunan di Desa Tonrongnge Kecamatan Baranti Kabupaten Sidenreng Rappang. Jurnal Ilmiah Clean Government, 2(Desember), 67-84. 
http://lonsuit.unismuhluwuk.ac.id/index.php/clean/article/view/213

Mustanir, A., \& Rusdi, M. (2018). Participatory Rural Appraisal (PRA) Sebagai Sarana Dakwah Muhammadiyah Pada Perencanaan Pembangunan di Kabupaten Sidenreng Rappang. Prosiding Konferensi Nasional Ke-8 Asosiasi Program Pascasarjana Perguruan Tinggi Muhammadiyah Aisyiyah (APPPTMA), 8(3 Des), 467-475. http://asosiasipascaptm.or.id/index.php/publikasi/prosiding-konferensi-nasional-appptmake-8

Mustanir, A., Samad, Z., Jabbar, A., Ibrahim, M., \& Juniati, J. (2019). Kepemimpinan Lurah Terhadap Pemberdayaan Masyarakat Di Kelurahan Lautang Benteng Kabupaten Sidenreng Rappang. Journal of Social Politics and Governance (JSPG), 1(2), 99-118. https://doi.org/10.24076/jspg.v1i2.185

Transect Pada Perencanaan Pembangunan Partisipatif. (2018). Ilmiah Ilmu Administrasi Publik, $8(2), 21-31$.

Yenni Jamal, Ahmad Mustanir, A. L. (2020). Penerapan Prinsip Good Governance Terhadap Aparatur Desa Dalam Pelayanan Publik Di Desa Ciro-Ciroe Kecamatan Watang Pulu Kabupaten Sidenreng Rappang. PRAJA: Jurnal Ilmiah Pemerintahan, 8(3), 207-212. https://doi.org/10.51817/prj.v8i3.298

Zhilviana Sulaeman, Ahmad Mustanir, A. I. M. (2019). Partisipasi Masyarakat Terhadap Perwujudan Good Governance Di Desa Damai Kecamatan Watang Sidenreng Kabupaten Sidenreng Rappang. PRAJA: Jurnal Ilmiah Pemerintahan, 7(3), 88-92. https://doi.org/10.51817/prj.v7i3.374 